\title{
La parodia en la comedia animada estadounidense de prime time. El caso de la sitcom
}

\author{
Parodia Estatu Batuetako prime time-eko \\ animaziozko komedian. Sitcom-aren kasua
}

\section{Parody in American prime time animated comedy.The case of sitcom}

\section{Beatriz María Gómez Morales ${ }^{1}$}

\section{zer}

Vol. 20 - Núm. 39

ISSN: $1137-1102$

e-ISSN: $1989-631 \mathrm{X}$

DOI: $10.1387 /$ zer. 15519

pp. $67-83$

2015

Recibido el 28 de mayo de 2014, aceptado el 14 de septiembre de 2015.

\section{Resumen}

La comedia animada estadounidense de prime time se caracteriza por basar su estructura narrativa en la parodia de otros géneros y formatos, principalmente la sitcom. A través del análisis textual, esta investigación examina las estrategias paródicas que emplea la comedia animada para transformar los elementos narrativos que definen a la sitcom: finales felices, estructura cíclica, personajes estereotipados y risas enlatadas. El estudio concluye que la parodia televisiva, representada por las comedias animadas, funciona como herramienta de reflexión y revisión de los contenidos de ficción y entretenimiento.

Palabras clave: Comedia animada, parodia, géneros televisivos, Los Simpson.

\section{Laburpena}

Prime-time-eko Estatu Batuetako animaziozko komediaren egitura narratiboa beste genero eta formatoen parodian oinarritzen da, sitcom-arena bereziki. Testu-analisiaren bitartez, ikerketa honek sitcom-aren elementu narratiboak eraldatzeko animaziozko komediak erabiltzen dituen parodia-estrategiak aztertzen ditu: amaiera zoriontsuak, egitura ziklikoak, pertsonaia estereotipatuak eta aurregrabatutako barreak. Ikerketaren emaitza moduan, animaziozko komediek irudikatzen duten telebista-parodiak fikziozko eta entretenimendurako edukien inguruko hausnarketa eta errebisioa egiten duela ondorioztatu daiteke.

Gako-hitzak: Animaziozko komedia, parodia, telebista-generoak, The Simpsons.

\footnotetext{
${ }^{1}$ Universitat Autònoma de Barcelona, beatrizmaria.gomez@e-campus.uab.cat
} 


\begin{abstract}
American prime time animated comedy is characterized by its narrative structure based on parody other genres and formats, mainly the sitcom. Through textual analysis, this research examines the parodic strategies used by the animated comedy to transform narrative elements that define the sitcom: happy endings, cyclic structure, stereotypical characters and canned laughter. The study concludes that TV parody, represented by animated comedies, works as a tool for reflection and review of fictional and entertainment contents.
\end{abstract}

Keywords: Animated comedy, parody, television genres, The Simpsons. 


\section{Introducción}

Las parodias en televisión han sido muy frecuentes dentro de los programas de sketches, pero los relatos autónomos e independientes dedicados a parodiar un género o formato específico no han sido muy numerosos. Sin duda, el más famoso de todos ellos fue Get Smart (El Superagente 86, NBC, 1965-70). Esta serie, aunque claramente era una parodia del género cinematográfico simbolizado por James Bond, también fue una respuesta al género del espionaje en la televisión, principalmente representado por series como Foreign Intrigue (syndication, 1951-55), The Man from U.N.C.L.E. (NBC, 1964-68) o I Spy (NBC, 1965-68).

Tras el éxito de Get Smart, otras parodias del género de espías, así como de otros géneros y formatos, probaron suerte pero no la tuvieron. Producciones como Mary Hartman, Mary Hartman (Syndication, 1976-77) y Soap (ABC, 1977-81), parodias del soap opera, o Police Squad! (ABC, 1982) y Sledge Hammer! (ABC, 1986-88), hipertextos del policiaco, no disfrutaron de una larga trayectoria pero, por diferentes razones, se han convertido en referentes de televisión paródica. Por su parte, $\mathrm{Ma}$ rried...with Children (Matrimonio con hijos, Fox, 1987-97), además de llegar a ser un referente, consiguió mantenerse en antena durante 10 años y ofreció una extraordinaria parodia de la sitcom doméstica. Estrenada dos años después, Los Simpson se apuntó a la iniciativa de Married...with Children y lleva más de 25 años llamando la atención sobre la estructura narrativa y los elementos característicos de este formato.

Pero Los Simpson no constituye una excepción. Como icono de la comedia animada de prime time, representa un subgénero caracterizado por la transformación y estilización paródica, así como la autorreflexividad y la intertextualidad (Gómez, 2014). De las 111 comedias animadas estrenadas en prime time entre 1960 y 2013, 43 son claras parodias de otros géneros y subgéneros televisivos: 17 parodian las sitcoms $^{2}, 6$ los programas de superhéroes ${ }^{3}, 3$ los policíacos ${ }^{4}, 3$ la ciencia ficción ${ }^{5}, 3$ el teen drama ${ }^{6}, 2$ los espectáculos deportivos ${ }^{7}$ y 2 el anime 8 . Las 7 comedias restantes son ejemplos únicos de parodias al western (Saddle Rash, Adult Swim, 2002), el talk show (Space Ghost Coast to Coast, Cartoon Network / Adult Swim/ Game

\footnotetext{
2 Allen Gregory (Fox, 2011), American Dad! (Fox, 2005-), Bob's Burguers (Fox, 2011-), The Brak Show (Adult Swim, 2000-03), The Cleveland Show (Fox, 2009-13), Dilbert (UPN, 1999-00), Duckman (USA Network, 1994-97), Family Guy (Fox, 1999-), Father of the Pride (NBC, 2004), The Flintstones (ABC, 1960-66), The Goode Family (ABC, 2009), The Jetsons (ABC, 1962-63), King of the Hill (Fox/ Syndication, 1997-09/2010), The Oblongs (The WB/ Adult Swim, 2001/2002), The Simpsons (Fox, 1989-), South Park (Comedy Central, 1997-) y Wait Till Your Father Gets Home (Syndication, 1972-74).

3 Aqua Teen Hunger Force (Adult Swim, 2001-), Freak Show (Comedy Central, 2006), Frisky Dingo (Adult Swim, 2006-08), Harvey Birdman, Attorney at Law (Adult Swim, 2000-07), Minoriteam (Adult Swim, 2005-06) y Stripperella (Spike TV, 2003-04).

4 Assy McGee (Adult Swim, 2006-08), Fish Police (CBS, 1992) y Stroker and Hoop (Adult Swim, 2004-05).

5 Futurama (Fox/ Comedy Central, 1999-03/2008-13), Sealab 2021 (Adult Swim, 2000-05) y Tripping the Rift (Syfy, 2004-07).

${ }^{6}$ Clone High (MTV, 2002-03), Daria (MTV, 1997-02) y High School USA (Fox, 2013).

7 Celebrity Deathmatch (MTV/ MTV2, 1998-2002/2006-08) y Mongo Wrestling Alliance (Adult Swim, 2011).

8 Perfect Hair Forever (Adult Swim, 2004-07) y Titan Maximum (Adult Swim, 2009).
} 
Tap, 1994-01/2001-04/2006-08), el reality show (Drawn Together, Comedy Central, 2004-07), los programas del corazón (Starveillance, E!, 2007), los de espías (Archer, FX, 2010-), los de espada y brujería (Korgoth of Barbaria, Adult Swim, 2006) y los de acción y aventura (The Venture Bros., Adult Swim, 2004-).

La comedia animada de prime time posee una gran capacidad para deconstruir géneros y formatos. Como texto paródico, establece de forma simultánea una relación de similitud y diferencia con el texto parodiado. Para poder ser reconocidas como parodias, las comedias animadas reiteran algunos de los elementos definitorios del género o formato que les da origen, al mismo tiempo que modifican otros: los invierten o exageran para llamar la atención sobre dichos elementos y así evidenciar su artificialidad. En palabras de Bajtín (1989: 421), la parodia representa y ridiculiza, con mayor o menor profundidad, los rasgos de un género o estilo. Precisamente, examinar cómo la comedia animada lleva a cabo este proceso simultáneo de representación y ridiculización de la sitcom tradicional es el objetivo de esta investigación. Los Simpson ha suscitado un interés académico sorprendente, que se ha traducido en una amplísima bibliografía sobre la serie. Sin embargo, muy poco se ha dicho sobre la serie como sitcom (Gray, 2006; Turner, 2004). En la misma línea, las dos únicas publicaciones dedicadas a la comedia animada (Stabile y Harrison, 2003; Booker, 2006) destacan el componente animado de las series, mientras dejan de lado su estructura narrativa y sus características como comedia de situación.

\section{Metodología}

En este artículo se pretende avanzar en el estudio de la comedia animada de prime time y analizar la forma en la que dicho subgénero parodia otros textos, concretamente la sitcom, el formato con mayor número de hipertextos entre las comedias animadas. Para ello se recurre al análisis textual (Casetti y Di Chio, 1999). Las unidades de dicho análisis han sido definidas a partir de los rasgos narrativos y estilísticos definitorios de la comedia de situación. A pesar del extenso debate que se ha generado en torno a la definición de la sitcom, hay cuatro elementos característicos que se repiten en las múltiples aproximaciones de los diferentes autores (Mintz, 1985; Neale y Krutnik, 1990; Brown, 1992; Carlson, 1993; Marc, 1997; Álvarez Berciano, 1999; Crisell, 2006; Mills, 2005; Gordillo, 2009): los finales felices, la estructura cíclica, las risas enlatadas y los personajes estereotipados. Dichos elementos son precisamente las cuatro unidades de análisis sobre las que se sustenta este estudio y a partir de las cuales se estructura el artículo ${ }^{9}$. Por su parte, el esquema de lectura, dada la carencia de referentes en el ámbito televisivo, deriva del modelo teórico-analítico desarrollado por Harries (2000) para el análisis cinematográfico. El autor identifica seis herramientas paródicas (reiteración, inversión, exageración, introducción de elementos extraños, direccionalidad errónea y literación) y a partir de estas se abordan las transformaciones paródicas que sufren las convenciones narrativas de la sitcom.

El bloque de animación de prime time más popular e influyente de la televisión norteamericana, "Animation Domination" de Fox, constituye la muestra de análisis

\footnotetext{
9 Es preciso señalar que otros rasgos característicos de la sitcom, como la iluminación plana o la grabación multicámara, han sido descartados en este estudio por la imposibilidad de identificar, la mayor parte de las veces, su utilización en el formato de la animación limitada (Mittell, 2004).
} 
de la investigación. Dicho bloque ha estado compuesto, en diferentes temporadas, por Los Simpson (The Simpsons, 1989-), El rey de la colina (King of the Hills, 199709), Padre de familia (Family Guy, 1999-), American Dad! (2005-) y El show de Cleveland (The Cleveland Show, 2009-13) ${ }^{10}$. En total, se contemplan cinco comedias que parodian la comedia de situación, concretamente la doméstica, y que, en conjunto, suman 61 temporadas y 1.239 episodios.

\section{Los finales felices}

La sitcom tradicional se caracteriza por los finales felices y artificiales que sacrifican la lógica y la credibilidad en aras de resolver todos los problemas y atar todo los cabos sueltos de forma casi mágica. Además, en cada episodio, los personajes se enfrentan a nuevas situaciones que los abocan a tomar decisiones éticas y morales de las que aprenden una valiosa lección. En definitiva, al final de cada episodio, los personajes son más sabios y más felices. Por el contrario, en la sitcom animada los finales felices y aleccionadores no siempre son necesarios.

En las comedias animadas, la carencia de un final feliz perfecto no se considera un defecto, sino que los guionistas se valen precisamente de este elemento de la sitcom para parodiar su artificialidad. A veces, los finales son felices, pero es muy común que dichas series apuesten por los finales alternativos que juegan con el tradicional final feliz y terminen con una situación absurda que únicamente pretende hacernos reír. Por ejemplo, al final del episodio "La mano que mece la silla de ruedas" (PF, T9.E12) $)^{11}$, Brian tiene la oportunidad de matar al clon malvado de Stewie pero, en medio de una lucha, no consigue identificar cual de los dos Stewies es el malvado. Finalmente, Brian decide ponerlos a prueba y les pide que miren sus pies. Brian sabe que el verdadero Stewie es incapaz de ver sus propios pies y no reírse de ellos; por ello, dispara al Stewie que no ríe y el Stewie sobreviviente le da las gracias. Sin embargo, abrazado a Brian de regreso a casa, Stewie se gira hacia la cámara, sonríe maliciosamente, sus ojos se tiñen de amarillo y de fondo escuchamos la risa de Vincent Price, demostrando así que el Stewie malvado es el que ha sobrevivido. De esta manera, el episodio no presenta un final feliz de sitcom, sino la reproducción de la secuencia final del video musical Thiller (1983) de Michael Jackson, inspirado en numerosas películas de terror.

En "Dia-BILL-ic Shock" (RC, T13.E1), un presumible final feliz también es interrumpido de forma abrupta. En dicho episodio, Bill descubre que todos los esfuerzos que ha hecho por cuidar su salud han valido la pena y que es admirable como ha conseguido curarse él mismo de la diabetes. Sin embargo, este final feliz y edificante es tergiversado justo en la última secuencia, cuando el mismo Bill, ya no tan admirable, decide visitar al médico grosero y egocéntrico que le diagnosticó la enfermedad y le

\footnotetext{
${ }^{10}$ El bloque ha acogido otras series como Bob's Burguers (2011-), Allen Gregory (2011) y Napoleon Dynamite (2012). No obstante, son desestimadas para forma parte de la muestra por su falta de trayectoria y popularidad.

${ }^{11}$ Para facilitar la localización de los episodios mencionados, cada cita incluye, entre paréntesis, las iniciales del nombre de la serie (LS para Los Simpson, RC para El rey de la colina, PF para Padre de familia, AD para American Dad y SC para El show de Cleveland), el número de la temporada y de episodio (T para temporada y E para episodio).
} 
aseguró que estaba condenado a una muerte lenta y angustiosa, para vengarse de él dándole una paliza.

En los ejemplos anteriores se manifiestan con claridad dos de las seis estrategias del cine paródico identificadas por Dan Harries (2000): la inclusión de elementos extraños y la direccionalidad errónea. En el primer caso, la recreación del final de un video musical es un ejemplo de lo que Harries denomina inclusión de elementos extraños, es decir, de elementos que chocan, no corresponden o carecen de relación alguna con el léxico, la sintaxis o el estilo del referente sobre el que se construye la parodia, en este caso la sitcom. El segundo ejemplo emplea la direccionalidad errónea, de manera que al final del episodio se reproduce la estructura narrativa del texto original solo para transformarla posteriormente. Dicha transformación crea consecuencias imprevistas por el lector, ya que en realidad no ocurre lo que éste espera, pues no se cumplen las convenciones del formato, sino que sucede algo totalmente diferente.

Los finales de la sitcom tradicional también se caracterizan por contener siempre una moraleja o una lección que enseñar. Algo positivo, moral y edificante debe surgir de cada historia. Precisamente esta es la característica que toma el episodio "Un hombrecito en el instituto" (SC, T2.E5) para parodiar la artificialidad de la sitcom. Cleveland, como entrenador del equipo de beisbol del instituto local, hace pasar a uno de sus mejores amigos, Holt, por un estudiante de intercambio para que le ayude a ganar el campeonato estatal. Cleveland Jr., siguiendo el ejemplo de su padre, engaña al profesor del taller de carpintería presentando como suyo el proyecto de su amigo Ernie. Cuando Cleveland Jr. se lo explica a su padre, éste se da cuenta del gran error que ha cometido y saca a Holt del partido, decisión que le cuesta la victoria deportiva. Pocos minutos antes del final del episodio, Cleveland mira al entrenador campeón y le dice a su esposa: "Bueno Donna, el puede haber ganado el anillo y el campeonato, pero yo tengo la satisfacción de una conciencia limpia. Hice algo extraordinario hoy". Pero Donna le responde:

En realidad no. Hiciste trampa para llegar al campeonato y después te acobardaste y no pudiste llegar hasta el final. ¿Te das cuenta de que eliminaste de la competición a tres equipos que merecían participar? Por tanto, en realidad no hiciste nada grandioso.

Cleveland la contradice y afirma: "No, lo hice. No lo entenderías. Son cosas de hombres. Conciencia limpia, corazón lleno, no puedo perder". Donna, sin ánimos de seguir discutiendo, dice: "Lo que sea. Solo me alegro de no haber sabido nada al respecto". Donna, como madre de familia y voz de la razón, hace ver a Cleveland que no tiene sentido lo que está diciendo y nos evidencia la artificialidad de los finales felices a costa de sacrificar la lógica y olvidar todos los errores cometidos, como si nada de aquello hubiese pasado. Para confirmar que Cleveland, ni nadie, ha aprendido algo de todo lo sucedido, inmediatamente después de la conversación con Donna, aparece toda la familia entre el público de una obra musical y vemos unas letras sobreimpresas en la parte inferior de la pantalla que dicen: 
Seis días después, instado por su padre, Cleveland Jr. confesó que había hecho trampa y obtuvo una "F". Donna utilizó su ordenador en la oficina del director para aumentar la nota hasta una "B". Nadie aprendió nada.

Está claro que en este episodio la fórmula paródica de la que se valen los guionistas es la inversión. Esta estrategia, tal y como su nombre indica, señala la modificación de un elemento lexical, sintáctico o estilístico para que connote exactamente lo opuesto que en su referente original (Harries, 2000:37). Así, en este último ejemplo, la generación de las risas ha sido producto de la confrontación entre lo que tenían que haber dicho o hecho los personajes y su completo opuesto, que es lo que a fin de cuentas dicen o hacen.

Por el contrario, el final del episodio "Milhouse ya no vive aquí" (LS, T15.E12) parodia otro elementos de la sitcom, las frases cliché y edulcoradas con las que se cierran las historias, pero a través del uso de la reiteración. Esta fórmula se refiere al uso, evocación o citación de elementos y estructuras características del texto parodiado que marcan la semejanza sobre la que se establecerá la analogía entre los dos textos (Harries, 2000: 43). Así, el final de "Milhouse ya no vive aquí" no reta al espectador a descubrir los elementos parodiados, sino que abiertamente señala las convenciones narrativas de éste en la comedia de situación. En la última secuencia de dicho episodio, Bart y Lisa se reconcilian y terminan abrazándose, como en cualquier sitcom clásica. A continuación, aparece Isabel Sanford, más conocida por su personaje de Louise "Weezy" Jefferson en All in the family (Todo en familia, CBS, 1971-79) y The Jeffersons (CBS, 1975-85), en el museo de la radio y la televisión señalando como las sitcom suelen recurrir a los finales almibarados seguidos de un gag con el que aligerar tanto empacho: "Esto es lo que en las comedias de situación se conoce como 'un final sensiblero', un broche de oro sentimentaloide para dejar a la audiencia con una sensación agradable. Generalmente seguido por un chiste para la rebajar tanta sensiblería”. Acto seguido, Isabel señala una de las pantallas que tiene a su espalda y vemos una parodia de The Beverly Hillbillies (Los nuevos ricos, CBS, 1962-71) en la que Jethro anuncia a Granny que se une al ejército: "Granny, voy a matar a algunos del Vietcong". Y Granny le responde: "Bueno, pues yo no voy a cocinarlos". De esta forma, Los Simpson adopta la estructura del final feliz pero seguidamente pone al descubierto su artificialidad.

Por último, el episodio "Una piñata llamada Deseo" (AD, T7.E11) termina con una secuencia que parodia toda la estructura del final feliz: las frases cliché, la música nostálgica y melancólica, la resolución de todos los problemas y cabos sueltos en tan solo 22 minutos y las explicaciones poco convincentes. Al inicio del episodio, Steve propone a sus amigos celebrar una fiesta de pijamas. Sin embargo, sus amigos deciden no asistir porque todos los chicos del instituto se han burlado de ellos diciendo que ese tipo de fiesta es cosa de niños. Steve intenta convencerlos de lo contrario pero no lo consigue. Afligido, Steve decide pasar la noche en la casa del árbol y celebrar la fiesta él solo. De repente, aparecen Snot, Barry y Toshi, los amigos de Steve, y le explican que han recibido su correo electrónico y han cambiado de opinión. Justo en el momento en que Steve les informa de que él no ha enviado ningún correo, entra a la casa del árbol Ronnie, el quinto miembro del grupo de 
amigos de la infancia que hace algunos años se mudó de la ciudad, y asegura haber sido él quien escribió al resto de chicos. Los cinco amigos se reconcilian y deciden celebrar la fiesta. Mientras se divierten, Steve asume el rol de narrador y, de fondo, lo escuchamos diciendo:

\begin{abstract}
Esa noche tuvimos la mejor fiesta de pijamas de nuestras vidas. Tal vez porque sabíamos que sería la última. Por la mañana, nuestra infancia se habría evaporado como un sueño y entraríamos en el amanecer de la adultez. Nunca descubrimos cual de nosotros envió el correo electrónico a Ronnie. De hecho, hasta el día de hoy, estoy bastante seguro de que fue tan solo algún tío negro que nos escuchó planeando nuestra fiesta de pijamas en el salón de la pizzería, pero seguro que era alucinante.
\end{abstract}

La imagen y la voz off parodian el estilo narrativo popularizado por The wonder years (Aquellos maravillosos años, ABC, 1988-93), mientras que la ultima parte de la narración de Steve hace referencia a las explicaciones improvisadas e inverosímiles necesarias para la resolución de todos los conflictos. Por si fuera poco, las tiernas palabras de Steve no van acompañadas de imágenes de los cinco chicos jugando en su fiesta, que sería lo propio de una sitcom tradicional, sino que todos aparecen intentando hacerse una autofelación.

\title{
3. Estructura cíclica y memoria
}

La estructura narrativa de Los Simpson, El rey de la colina, Padre de familia, American Dad y El show de Cleveland es limitada. Cada episodio inicia con una fase de apertura habitual que, debido a un punto de giro, inaugura un conflicto que desestabiliza la normalidad. No obstante, la desestabilización es solo momentánea, dado que al final de cada episodio hay una restauración del orden doméstico y se regresa a la situación inicial. La sitcom siempre termina exactamente donde comenzó, puesto que su estructura narrativa está basada en la circularidad: después de media hora de diálogos e incidentes, los personajes se encuentran a sí mismos de nuevo en el punto de partida (Mintz, 1985; Crisell, 2006). El episodio "La chica sexy de la FOX" (PF, T7.E10) no solo acaba de la misma manera en que inicia, como todos los demás, sino que precisamente llama la atención sobre esta característica narrativa de la sitcom. En dicho episodio, Lois se convierte en reportera de Fox News pero, tal como se esperaba, al final del episodio deja de trabajar para la cadena. En la escena final del episodio, mientras la familia ve la televisión, Lois afirma: "Bueno, estoy feliz de que todo haya vuelto a la normalidad. No creo que esté hecha para ser reportera". Peter, intrigado por saber cómo dejó el trabajo, le pregunta: "Si, pero, por cierto, ¿cómo perdiste tu trabajo?" y Lois le responde: "Oh, no lo sé. ¿En realidad te importa, Peter? ¿Le importa de verdad a alguien?”. Peter, convencido que a estas alturas del relato eso ya no tiene importancia y consciente de que en el próximo episodio todo volverá a ser como antes, añade: "Si, tienes razón. La historia se ha acabado. Todo volverá a la normalidad la próxima semana. Así que, ¿a quién le importa?”. 
Ahora bien, para que la estructura cíclica de la sitcom se pueda mantener a lo largo, no solo de los episodios, sino también de toda la historia de la sitcom, es preciso que los acontecimientos de cada emisión no interfieran en el subsiguiente desarrollo de la trama, es decir, en los sucesos de los episodios posteriores. Por ello, es regla general de la comedia de situación que los episodios no se refieran a eventos sucedidos en el pasado (Mills, 2005: 27). De hecho, mientras la soap opera mantiene de forma meticulosa el curso temporal de la trama, la sitcom estimula a la audiencia a 'olvidar' muchos de los sucesos ocurridos con anterioridad (Neale y Krutnik, 1990: 235).

Precisamente de esta característica se mofa el episodio "El director y el pillo" (LS, T9.E2). En esta oportunidad descubrimos que el director de la escuela local, Seymour Skinner, no es quien dice ser. Su verdadero nombre es Armin Tamzarian y robó la identidad de Skinner, a quien conoció mientras servía en la Guerra de Vietnam, en un acto de compasión: Tamzarian es enviado a casa de la madre de Skinner para notificarle que su hijo ha muerto en combate; sin embargo, ella lo confunde con su hijo y Tamzarian, para ahorrarle el sufrimiento, no la corrige en su error. Sin embargo, Skinner no muere en la guerra y reaparece muchos años después en Springfield, donde consigue ser odiado por todo el pueblo y finalmente expulsado. En la última escena del episodio, el juez del pueblo le devuelve a Armin Tamzarian no solo el nombre de Skinner, sino también su vida e historia personal:

Juez Schnider: Por la autoridad de la ciudad de Springfield, le confiero el nombre de Seymour Skinner, al igual que su pasado, su presente, su futuro, y su madre.

Director Skinner (antes Armin Tamzarian): De acuerdo.

Juez Schnider: Y además decreto que todo volverá a ser como era antes de que todo esto sucediera. Y nadie volverá a mencionarlo... bajo pena de tortura.

De esta manera, la serie ratifica que cada episodio siempre debe terminar exactamente donde comenzó y el conflicto narrativo no debe conducir a una situación distinta a la de apertura. Aunque sea por que un juez lo ordene bajo pena de tortura.

La no interferencia del pasado en el presente o el futuro se debe, en gran medida, a la ausencia de memoria en los personajes, quienes se enfrentan una y otra vez a situaciones semejantes sin recordar las experiencias anteriores. En las comedias animadas, aunque los personajes también sufren 'amnesia' ocasionalmente, se tienden a cruzar unos episodios con otros. No obstante, no parece haber un modelo para poder determinar qué aspectos son continuos y cuáles no. Así pues, Los Simpson, El rey de la colina, Padre de familia, American Dad y El show de Cleveland son capaces de desarrollar una nueva línea argumental a partir de ciertas tramas anteriores, mientras que otras son olvidadas o incluso contradichas. Por ejemplo, el episodio "Papá rabioso: la película" (LS, T22.E14) da continuidad a una historia iniciada nueve temporadas antes, en "Estoy verde de rabia" (LS, T13.E18), cuando Bart crea un comic inspirado en Homer. Por el contrario, en "Lisa, la Simpson" (LS, T9.E17) se explica la estupidez de Homer como consecuencia del "gen Simpson" pero, tres 
temporadas después, en "HOMЯ” (LS, T12.E9), Homer descubre que la causa de su bajo coeficiente intelectual es una cera para colorear que tiene atascada en el cerebro.

Las comedias animadas crean un vínculo de complicidad con el espectador por medio de sus múltiples referencias intertextuales, pero refuerzan dicho vínculo a través de los guiños a la historia interna de la serie. Por ejemplo, en el episodio "Tiegs para dos" (PF, T9.E14), mientras salen de un elegante restaurante, Quagmire y Brian ven entrando a Meg y al alcalde de Quahog, Adam West. Ambos quedan muy sorprendidos y Meg dice: "Sí, sigue pasando algunas veces". Este comentario de Meg hace referencia a la relación sentimental que había iniciado con West en el episodio "Garganta profunda" (PF, T4.E23). Al final de dicho episodio, Meg y el alcalde se veían abocados a terminar con su relación; sin embargo, las anteriores palabras de Meg demuestran lo contrario.

En otros episodios no se parodia la sitcom al recordar sucesos anteriores, sino resaltando la forma peculiar en que funciona la memoria de los personajes, que como la de las mismas series, es aleatoria. La facilidad con la que los personajes de la sitcom pierden la memoria y la forma arbitraria en que vuelven los recuerdos está perfectamente ilustrada en el episodio "El hotel de los pedos rotos" (AD, T7.E9). Después de sufrir una grave indigestión y llenar la casa con flatulencias tóxicas, Roger obliga a toda la familia Smith a mudarse temporalmente a un hotel. Sintiéndose culpable, el mismo Roger decide invitarlos y Francine le pregunta cómo puede permitírselo, a lo que Roger responde:

Estuve aquí en los años ochenta y sufrí un terrible accidente. Para evitar la demanda, el hotel me dio una semana de habitaciones gratis. La verdad es que me había olvidado de todo el asunto hasta hoy. Ese pedo removió algunos recuerdos olvidados.

Pero, de la misma manera que parece haber algunos gases que ayudan a recobrar la memoria, hay otros que parecen ayudar a perderla. Por ejemplo, en "El azul y el gris" (LS, T22.E13), Marge se sorprende al descubrir que le están saliendo canas; aunque hacia 17 años, en el episodio "Secretos de un matrimonio con éxito" (LS, T5.E22) se había establecido que Marge tenía el pelo gris, de hecho, tuvo canas de forma prematura. Sin embargo, Julio, el peluquero de Marge, tiene una explicación para que ella haya olvidado que se tinturaba el cabello: los gases que emite la coloración capilar que suele usar Marge causan pérdida parcial de la memoria y borran la experiencia en la peluquería.

\section{Música y acompañamiento sonoro}

Además de los mecanismos narrativos, la sitcom tiene algunos elementos estilísticos propios. El más relevante de ellos es la risa enlatada. Inmaculada Gordillo señala que "constituye una figura estilística particular, integrante del género de la comedia de situación desde 1950" (Gordillo, 2009:160); mientras que Álvarez Berciano es más contundente al afirmar que "la risa enlatada es con toda seguridad el elemento 
más denostado fuera y dentro de la industria, y el que más peso ha tenido sobre la imagen del género" (Âlvarez Berciano, 1999: 11). A pesar de las numerosas críticas y lo molestas que puedan resultar para muchos, lo cierto es que la risa enlatada ha acompañado a la comedia de situación desde sus inicios y muy pocas producciones han conseguido el éxito habiendo prescindido de ella. No obstante, las comedias animadas de prime time no incluyen de forma regular risas pregrabadas. En las pocas ocasiones en las que son presentadas, así como otro tipo de exclamaciones propias de los programas con público en vivo, tienen como único propósito reforzar la parodia a la sitcom tradicional.

Al inicio de "Los dos candidatos" (PF, T2.E10) aparece Peter, sin pantalones, saliendo de la casa en busca de Lois. De fondo se escuchan las risas de una supuesta audiencia y nos muestran que, efectivamente, en frente del hogar Griffin hay una grada llena de personas viendo la serie "en vivo". Peter los mira y dice: "Estaré feliz cuando este público de estudio se vaya del barrio". Acto seguido, también Brian sale de la casa y avisa a Lois y Peter que han llamado del instituto de Chris porque éste se ha metido en problemas. La audiencia exclama al unísono "Ohhh" y Peter responde: “ ¡Ya está bien! ¡Voy a llamar a la policía!”. Al final del episodio, después de que Stewie aparezca cantando, volvemos a escuchar las risas enlatadas y Stewie dice: “Malditos todos!” y empieza a disparar hacia la audiencia. El segmento anterior no solo parodia las risas enlatadas y su carácter predecible, sino también la forma en la que interrumpen la narración y lo molestas que pueden llegar a ser, en este caso, incluso para los mismos personajes de la serie.

Otra forma de parodiar los códigos sonoros es transformando elementos tradicionalmente extradiegéticos en diegéticos. En el episodio "Los expedientes de Springfield" (LS, T8.E10), Homer se ve obligado a ir a casa caminando debido a su estado de embriaguez. El camino que decide tomar lo conduce a una carretera solitaria y oscura. Mientras vemos a Homer caminar nervioso, se escuchan de fondo "The murder" ("El asesinato"), la famosa pieza musical de la escena de la ducha de Psycho (Psicosis, Alfred Hitchcock, 1960). De repente, Homer divisa un vehículo que se dirige hacia él y el volumen de la música aumenta a medida que éste se acerca. Justo antes de ser alcanzado por el vehículo, Homer se aparta del medio de la carretera y descubre que el vehículo en cuestión es el autobús de la Filarmónica de Springfield, que tiene una parada justo donde Homer se encuentra. Del autobús baja una violinista, que como el resto del grupo, continúa tocando su instrumento y empieza a caminar en dirección contraria a Homer. Tras marcharse el autobús y la violinista, la música empieza a disiparse hasta desaparecer por completo. De forma clásica, las piezas musicales se introducen en la escena de forma extradiegética. Sin embargo, en el caso de un texto paródico como Los Simpson, la fuente musical, en contra de la convención del uso no diegético, es presentada de forma visual y se convierte en un elemento diegético.

También en el episodio "El hotel de los pedos rotos" (AD, T7.E9) se reproduce una secuencia en la que un elemento extradiegético se convierte en intradiegético, en este caso la figura del narrador. A través de la estrategia de la voz en off, a lo largo del episodio se escucha en diversas ocasiones un narrador omnisciente. En la última escena, aparece Francine, de espaldas, caminando por la calle en la que vive, mientras escuchamos, una vez más, la voz en off que dice: "Y desde ese momento, 
Francine convirtió el jueves en su día. Un día para hacer lo que le apeteciera. ¡Sí, chica! ¡Haz lo tuyo! ¡Sigue con tu jueves!”. Francine, como si también hubiese escuchado la voz, se da la vuelta rápidamente para ver de dónde proviene. Sin embargo, y a diferencia del espectador, no consigue ver a un hombre que se esconde detrás de unos arbustos, el supuesto narrador. El hombre, al asegurarse que Francine no lo ha descubierto, añade: "Tío, eso estuvo cerca". De esta manera, un narrador extradiegético heterodiegético se convierte en intradiegético heterodiegético, es decir, que un narrador en primer grado de la narración (fuera de cualquier diégesis), que cuenta una historia de la que está ausente, es figurativizado y convertido en un personaje de la historia narrada, que, a su vez, narra otra historia inserta en la primera (narración en segundo grado), pero de la cual también está ausente y solo conoce a través de otras fuentes (Genette, 1989b, p. 302).

La transformación de un elemento extradiegético en diegético constituye otra de las estrategias paródicas clasificadas por Harries: la literación. Dicha estrategia hace referencia a la introducción de bromas, visuales o verbales, para hacer "literal" el proceso de construcción del texto. Por ejemplo, en los tres últimos ejemplos, así como en los casos en que es presentada de forma explícita la audiencia en vivo, se hace "literal" la fuente sonora y se pone de manifiesto un elemento del relato que pertenece al mundo externo de la narración.

\section{La familia protagonista}

Las cinco series animadas que conforman la muestra son comedias de situación domésticas, también conocidas como domcoms, y están protagonizadas por familias nucleares: madre, padre y entre dos y tres hijos. Los Simpson (Los Simpson), los Hill (El rey de la colina), los Griffin (Padre de familia), los Smith (American Dad) y los Brown-Tubbs (El show de Cleveland) son parodias de la familia "ideal" representada por la sitcom doméstica americana. Estas familias son la antítesis de la familia presentada en la comedia de situación de la posguerra, como los Anderson (Father knows best, CBS, 1954-60) y los Cleaver (Leave it to Beaver, CBS, 1957-58; ABC, 1958-63), o de comedias más recientes como los Huxtable (The Cosby Show [La hora de Bill Cosby], NBC, 1984-92) o los Seaver (Growing Pains [Los problemas crecen], ABC, 1985-92). Todas estas familias y las relaciones que se entretejían dentro de ellas reforzaban el mito de la fuerza familiar por encima de todos los problemas, mientras que el mensaje de las comedias animadas suele ser que la convivencia familiar es complicada y que la unidad familiar no es suficiente para hacer frente a todas las dificultades.

\subsection{Los padres}

Butsch señala que el padre de clase media es representado como un padre sensible, maduro y sabio (2005: 117). Por el contrario, la devaluación del hombre de clase trabajadora es uno de los patrones más repetidos en los cincuenta años de la comedia de situación. Se trata de padres tontos, irresponsables y carentes de sentido común, que suelen tener buenas intenciones y ser queridos, pero no respetados ni imitados (Butsch, 2005: 115-16). Así, para la caracterización del padre en la comedia animada 
se emplea el recurso de la inversión, en relación al progenitor de clase media, y la reiteración o la exageración respecto al padre de clase trabajadora. De manera que, por ejemplo, Homer (Los Simpson) representa la antítesis de Jim Anderson (Father knows best, CBS, 1954-60), pero un sucesor para Ralph Kramden (The Honeymooners, CBS, 1955-56), Pedro Picapiedra (The Flintstones [Los Picapiedra], ABC, 1960-66) o Archie Bunker (All in the family [Todo en familia], CBS, 1971-79).

Homer, como Peter (Padre de familia), Stan (American Dad) y Cleveland (El show de Cleveland), se recrea a sí mismo en cada episodio, explorando la pluralidad de representaciones de la masculinidad (Williams-Rautiola: 2006). Es el hombre centrado y el ansioso; el padre entregado y el histérico; el esposo desagradecido y el romántico; el empleado inepto y el autónomo emprendedor. Por el contrario, la masculinidad hegemónica de Hank Hill (El rey de la colina) no se reinventa, sino que es puesta a prueba por una sociedad cambiante y por su afeminado hijo, Bobby. Hank es un personaje animado complejo, no es un "paleto sureño", ni un "gilipollas de Hollywood", tal como él mismo señala en "A Rover Runs Through It" (RC, T9.E1). Las convenciones de la animación añaden poco a la caracterización de Hank, ya que de él no esperamos cualquier tipo de locura, sino siempre la respuesta de un hombre integro, modesto, púdico y de moral fuerte. Los rasgos señalados por Butsch, descritos antes, también están presentes en El rey de la colina, pero no en el personaje de Hank, sino en los de sus tres mejores amigos: Dale, Bill y Jeff.

\subsection{Las madres}

La caracterización negativa del padre se acentúa en contraste con la de la esposa, una mujer inteligente, racional, sensible, responsable y madura (Butsch, 2005: 116). A diferencia de los padres, las madres animadas televisivas rara vez fracasan en su rol doméstico, familiar o conyugal. Marge (Los Simpson), Peggy (El rey de la colina), Lois (Padre de familia), Francine (American Dad) y Donna (El show de Cleveland) personifican y reiteran el rol de ama de casa abnegada de la sitcom tradicional, representado por June Cleaver (Leave it to Beaver, ABC, 1957-63) o Edith Bunker (All in the family [Todo en familia], CBS, 1971-79). Las madres animadas, como las progenitoras de sitcoms clásicas, aparecen día a día lidiando con genuinos problemas familiares y se encargan de todo lo relativo a la vivienda familiar. Sobre ellas no solo recae el rol doméstico, sino la estabilidad de todo el hogar. Sin ellas la unidad familiar, física y emocionalmente, se vendría abajo.

Su escenario principal es, en consecuencia, el hogar familiar. Marge, Lois y Francine han tenido pequeñas incursiones en el mundo laboral; sin embargo, éstas nunca se prolongan por más de un episodio. Peggy y Donna sí que tienen empleos fijos, pero eso tampoco ha impedido que la residencia familiar sea el escenario en el que más aparecen. De la misma manera que Elyse Keaton (Family Ties [Enredos de familia], NBC, 1982-89) y Clair Huxtable (The Cosby Show [La hora de Bill Cosby], NBC, 1984-92), Peggy y Donna suelen desarrollar sus actividades laborales fuera de las cámaras, de manera que su trabajo no interfiera con sus obligaciones domesticas y parentales (Snow y Snow, 2009: 184).

Pero a pesar de todas las similitudes, ocasionalmente las series animadas ridiculizan el estereotipo de la ama de casa idealizado en la ficción televisiva. Aunque 
generalmente las madres animadas suelen estar conformes con su rol, en algunos episodios se evidencia su frustración y cansancio respecto a las tareas del hogar. Por ejemplo, en "Homer solo" (LS, T3.E15), Marge sufre una crisis nerviosa y debe pasar unos días en una casa de reposo, y en "Simpsoncalifragilisticoespialid... joh! so" (LS, T8.E13) debe contratar a una persona que se encargue de los niños y de la casa porque el stress le ha provocado una pérdida de cabello alarmante. Mientras que Donna, en "Maratón de la cerveza" (SC, T2.E9), hace creer a su esposo e hijos que está gravemente lesionada para no tener que encargase de las tareas del hogar y que todos colaboren en casa.

Las madres animadas también distan mucho de sus antecesoras respeto al consumo de drogas. Por ejemplo, Francine ha tenido problemas con el alcohol y Donna con el tabaco. Sin embargo, es preciso señalar, que el uso de dichas sustancias es retratado de forma esporádica y puntual, mientras que el consumo de alcohol por parte de los padres es una práctica común y constituye su principal actividad social. Por el contrario, las madres aparecen en muy pocas ocasiones acompañadas de otras mujeres y ninguna de ellas tiene una amiga verdadera. En algún episodio concreto, Marge, Peggy, Lois, Francine y Donna han hecho una nueva amistad o han presentado una antigua amiga; no obstante, éstas no suelen ser personajes fijos de la serie como sí lo son los amigos de sus respectivas parejas. En "Mejores amigos para siempre" (SC, T3.E1), Donna evidencia este hecho cuando su marido, Cleveland, lamenta haber perdido contacto con sus amigos de Quahog, la ciudad en la que vivía antes de mudarse a Stoolbend. Dona, intentando animarlo, le dice que se concentre en sus nuevos amigos y destaca el hecho de que él tenga más amigos que ella, aunque él no haya vivido siempre en la misma ciudad y ella sí. Dona incluso se compara con Marge, Lois y Francine, quienes tampoco tienen un círculo de amigos estable como el de su pareja.

\subsection{Los hijos}

Al igual que los padres, los hijos animados también tienen algunas características estereotipadas y la construcción de los personajes sigue sustentándose, en parte, en la reiteración. Por ejemplo, Bart (Los Simpson) representan el típico 'hijo problema' de la sitcom tradicional representado por Mike Seaver de Growing Pains (Los problemas crecen, ABC, 1985-92) o T.J. Lambert de Step by step (Paso a paso, ABC, 1991-97; CBS, 1997-98). Sin embargo, los niños y adolescentes animados, de la misma forma que sus progenitores, son versiones exageradas e incluso invertidas de sus predecesores televisivos. Stewie (Padre de familia) es solo un bebé, y como tal, necesita ser alimentado y que le cambien los pañales, pero posee una inteligencia sobrenatural que solo emplea con propósitos malvados: intentar dominar el mundo y eliminar a su madre.

Los primogénitos de las cinco familias protagonistas son problemáticos y suelen tener ideas muy opuestas a las de sus padres, lo que los convierte en una decepción para estos últimos. Bart es conflictivo y no para de hacer travesuras con las que avergüenza a sus padres; Roberta (El show de Cleveland) es una adolescente caprichosa y rebelde a quien su madre es incapaz de controlar y Meg (Padre de familia) es el objeto de las bromas de toda su familia, carece de cualquier talento y sus padres la 
consideran el mayor fracaso de sus vidas. Por su parte, los casos de Hayley Smith (American Dad) y Bobby Hill (El rey de la colina) son más remarcables, pues no se trata de chicos conflictivos, sino que su propia personalidad desafía constantemente las creencias de sus respectivos padres. Hayley es totalmente opuesta a su padre, Stan. Ella es liberal y progresista en todos los aspectos de la vida, mientras él es un republicano conservador de ultraderecha. Por su parte, Bobby desafía el ideal de masculinidad de su padre. Al contrario de Hank, a Bobby no le gustan los deportes, no se preocupa por tener un cuerpo atlético y suele tener pasatiempos que su padre considera demasiado femeninos.

El segundo hijo o 'hermano del medio', como Lisa (Los Simpson), Steve (American Dad), Cleveland Jr. (El show de Cleveland) y Chris (Padre de familia), se caracterizan por ser inadaptados sociales. En el caso de los tres primeros, se trata de chicos sobresalientes en la escuela que intentan quitarse el estigma de empollón, mientras que en el caso de Chris el fracaso social se debe a su personalidad estúpida e irracional. Finalmente los hijos más pequeños, oscilan entre el típico bebé (Maggie, Los Simpson) y el monstruo malvado (Stewie), pasando por el preescolar popular (Rallo, El show de Cleveland).

\section{Conclusiones}

Las cinco comedias animadas de prime time analizadas en este estudio resaltan la artificialidad de las convenciones y estrategias estilísticas, sintácticas y narrativas de la sitcom. Sin embargo, al mismo tiempo que parodian y ponen en evidencia algunas de ellas, adoptan y reproducen otras. The Simpsons, King of the Hill, Family Guy, American Dad! y The Cleveland Show mantienen ciertas características de la sitcom doméstica, por ejemplo, retratan las situaciones típicas de este formato, están protagonizadas por un núcleo familiar, las historias son autónomas y autoconclusivas y el conflicto narrativo no suele llevar a los personajes a una situación distinta a la de apertura. No obstante, estas mismas comedias no recurren obligatoriamente al final feliz. En algunas ocasiones simplemente no hay final feliz, en otras el final feliz se ve interrumpido de golpe y en otras es completamente tergiversado. La estructura cíclica, aunque respetada en la mayoría de episodios, es desestabilizada a través de la citación a sucesos del pasado y la constante referencia a la obligatoria restauración de la situación inicial. Las comedias animadas tampoco incluyen risas enlatadas de forma habitual y solo las incorporan puntualmente para llamar la atención sobre su artificialidad. Por último, invierten y exageran el modelo de caracterización de los personajes, desde los padres hasta los hijos. Al crear personajes a partir de estereotipos y tomando rasgos tanto físicos como psicológicos de otros personajes famosos, las comedias animadas de prime time se ahorran tramas que de otra forma hubiesen tenido que desarrollar para conseguir el mismo fin.

Como textos paródicos, las comedias animadas de prime time intentan subrayar la monotonía y repetición del género o formato del que son hipertexto. La parodia, como manifestación próxima a la cultura negativa carnavalesca (Bajtín, 1987: 10), puede actuar con lógica transgresora e irreverente y cuestionar la legitimidad de otros textos. A pesar de su carácter temporal y una trasgresión siempre autorizada (Hutcheon, 1985: 75), la parodia, como el carnaval medieval y renacentista, ofrece 
una ocasión de liberación y escape que permite un cambio de percepción, que, en palabras de Bajtín, "preparaba el nacimiento de la nueva conciencia" (Bajtín, 1987: 86). De esta manera, los textos paródicos, como las comedias animadas, aunque solo pongan en evidencia la artificialidad de un género o formato consagrado de forma temporal, le proporciona a la audiencia un conocimiento sobre éstos que le permite reflexionar sobre sus tópicos con más distancia crítica y le invitan a participar en su deconstrucción.

Genette (1989a) recupera la interpretación etimológica de 'parodia' y señala que el prefijo 'para' no solo significa 'en contra', sino también 'al lado de' o 'junto a'. De esta manera, la parodia no solo funciona como herramienta crítica sino también como homenaje. Permite la reelaboración de un texto o una forma narrativa reconocida y elogiarla. Por ejemplo, The Venture Bros. (Adult Swim, 2003-), aunque basa su humor en la comparación entre ambos textos, ofrece un sincero homenaje a Johnny Quest (ABC, 1964-64). En cualquier caso, la parodia, como práctica hipertextual crítica o defensora, no intenta acabar con el género o formato al que hace referencia. Por el contrario, al llamar la atención sobre sus técnicas, estrategias y efectos, dinamiza su análisis, lo que posteriormente conlleva una nueva apreciación del género.

\section{Referencias bibliográficas}

ÁLVAREZ BERCIANO, Rosa (1999). La comedia enlatada: de Lucille Ball a Los Simpson. Barcelona: Gedisa.

BAJTín, Mijail (1987). La cultura popular en la Edad Media y en el Renacimiento. Madrid: Alianza.

BAJTÍN, Mijail (1989). Teoría y estética de la novela. Madrid: Taurus.

BOOKER, M. Keith (2006). Drawn to television: prime-time animation from The Flintstones to Family Guy. Westport, CT: Praeger.

BROWN, Les (1992). Les Brown's encyclopedia of television. Detroit: Gale Research.

BUTSCH, Richard (2005). Five decades and three hundred sitcoms about class and gender. En: EDGERTON, Gary R; ROSE, Brian G. (eds.). Thinking outside the box: a contemporary television genre reader. Lexington: University Press of Kentucky, pp. 111-135.

CASETTI, Francesco; DI CHIO, Federico (1999). Análisis de la televisión. Instrumentos, métodos y prácticas de investigación. Barcelona: Paidós.

CRISELL, Andrew (2006). A study of modern television. Thinking inside the box. New York: Palgrave Macmillan.

GENETTE, Gerard (1989a). Palimpsestos. La literatura en segundo grado. Madrid: Taurus.

GENETTE, Gerard (1989b). Figuras III. Barcelona: Lumen.

GÓMEZ MORALES, Beatriz (2014). La comedia animada de prime time en Estados Unidos. Un subgénero paródico, autorreflexivo e intertextual. En: Communication \& Society /Comunicación y Sociedad, vol. 27, n 1, pp. 127-142. 
GORDILLO, Inmaculada (2009). Manual de narrativa televisiva. Madrid: Síntesis. GRAY, Jonathan (2006). Watching with The Simpsons. Television, parody, and intertextuality. New York: Routledge.

HARRIES, Dan (2000). Film parody. London: BFI.

HUTCHEON, Linda (1985). A theory of parody: the teachings of twentieth-century art forms. New York: Methuen.

MARC, David (1997). Comic visions. Television comedy and American culture. Malden, MA: Blackwell.

MILLS, Brett (2005). Television Sitcom. London: BFI.

MINTZ, Larry (1985). Situation Comedy. En: ROSE, Brian G. (ed.). TV genres: a handbook and reference guide. Westport, CT: Greenwood Press, pp. 107-129.

MITTELL, Jason (2004). Genre and television: from cop shows to cartoon in American culture. New York: Routledge.

NEALE, Steve; KRUTNIK, Frank (1990). Popular film and television comedy. London: Routledge.

SNOW, Dale; SNOW, James (2009). Los Simpsons y la política del sexo. En: IRWIN, William; CONARD, Mark T.; SKOBLE, Aeon J. (eds.). Los Simpsons y la filosofía. Barcelona: Blackie Books, pp. 175-199.

STABILE, Carol; HARRISON, Mark (eds.) (2003). Prime time animation: television animation and American culture. New York: Routledge.

TURNER, Chris (2004). Planet Simpson: how a cartoon masterpiece documented an era and defined a generation. London: Ebury Press.

WILLIAMS-RAUTIOLA, Suzanne (2006). Animated fathers: representation of masculinity in The Simpsons and King of the Hill. En: BUCHAN, Suzanne (ed.). Animated Worlds. Eastleigh: John Libbey, pp. 95-112. 